\title{
CORRECTION
}

View Article Online

View Journal I View Issue

W) Check for updates

Cite this: RSC Adv., 2020, 10, 43960

DOI: 10.1039/dOra90129f

rsc.li/rsc-advances

\section{Correction: Three-dimensional directional nerve guide conduits fabricated by dopamine- functionalized conductive carbon nanofibre-based nanocomposite ink printing}

Shadi Houshyar, ${ }^{\text {a }}$ Mamatha M. Pillai, ${ }^{b}$ Tanushree Saha, ${ }^{a}$ G. Sathish-Kumar, ${ }^{c}$ Chaitali Dekiwadia, ${ }^{d}$ Satya Ranjan Sarker, ${ }^{\star e}$ R. Sivasubramanian, ${ }^{f}$ Robert A. Shanks ${ }^{g}$ and Amitava Bhattacharyya*c

Correction for 'Three-dimensional directional nerve guide conduits fabricated by dopamine-functionalized conductive carbon nanofibre-based nanocomposite ink printing' by Shadi Houshyar et al., RSC Adv., 2020, 10, 40351-40364, DOI: 10.1039/D0RA06556K.

The authors regret that an incorrect version of Fig. 2 was included in the original article. The correct version of Fig. 2 is presented below.

\footnotetext{
${ }^{a}$ School of Engineering, College of Science, Engineering and Health, RMIT University, Melbourne 3001, Australia. E-mail: shadi.houshyar@rmit.edu.au ${ }^{b}$ Tissue Engineering Laboratory, PSG Institute of Advanced Studies, Coimbatore-641004, India

'Functional, Innovative and Smart Textiles, PSG Institute of Advanced Studies, Coimbatore-641004, India. E-mail: abh@psgias.ac.in ${ }^{d} R M I T$ Microscopy and Microanalysis Facility, College of Science, Engineering and Health, RMIT University, Melbourne 3001, Australia ${ }^{e}$ Department of Biotechnology and Genetic Engineering, Jahangirnagar University, Savar, Dhaka-1342, Bangladesh ${ }^{f}$ Electrochemistry Laboratory, PSG Institute of Advanced Studies, Coimbatore-641004, India ${ }^{8}$ School of Science, College of Science, Engineering and Health, RMIT University, Melbourne 3000, Australia
} 

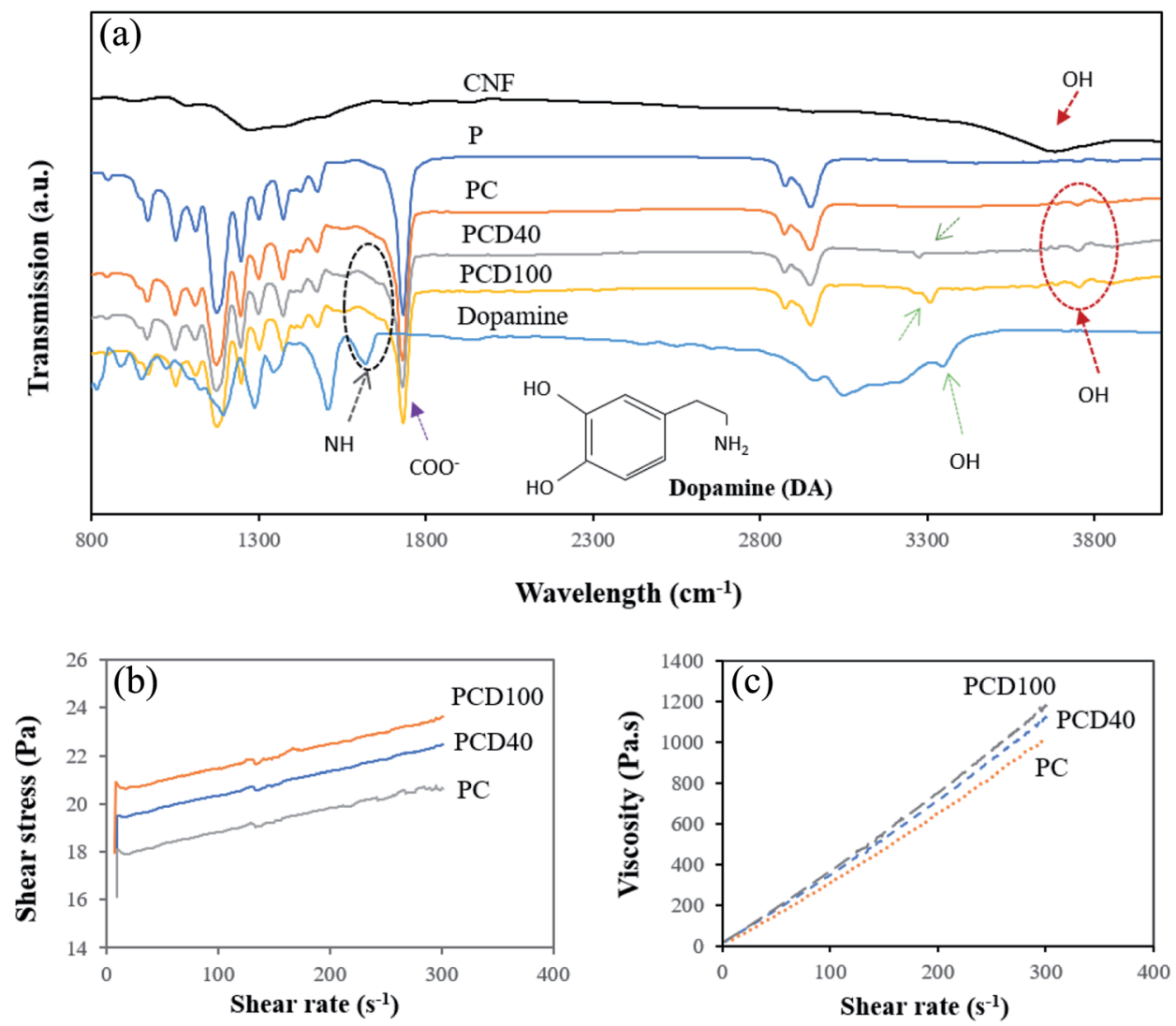

Fig. 2 (a) FTIR spectra of pure PCL and PCL printed with CNF and DA (40 and $100 \mu \mathrm{g} \mathrm{mL}^{-1}$ ), where circles emphasize the $\mathrm{OH}$ peak ( $3700 \mathrm{~cm}^{-1}$ ) of the carboxylated CNF and NH peak $\left(1565 \mathrm{~cm}^{-1}\right)$ of dopamine. (b) Shear stress of the CNF and CNF + DA nanocomposite inks versus shear rate. (c) Viscosity versus shear rate of the prepared nanocomposite inks.

The Royal Society of Chemistry apologises for these errors and any consequent inconvenience to authors and readers. 